\title{
LABORATORY EVALUATION OF HOT-MIX ASPHALT CONTAINING CONSTRUCTION AND DEMOLITION WASTE
}

\author{
A. R. Pasandín ${ }^{a,{ }^{*}}$ and I. Pérez ${ }^{a}$
}

${ }^{a}$ E. T. S. I. Caminos, Canales y Puertos, Universidade da Coruña. Campus de Elviña s/n, 15071. A Coruña, Spain

${ }^{*}$ Corresponding author. Tel.: +34-981167000. Fax: +34-981167170

E-mail addresses: arodriguezpa@udc.es (A.R. Pasandín), iperez@udc.es (I. Pérez)

\begin{abstract}
A laboratory study of the use of recycled concrete aggregates (RCA) from construction and demolition waste (CDW) in hot-mix asphalt (HMA) for base courses in pavements was conducted. HMA mixes containing $0 \%, 5 \%, 10 \%, 20 \%$ and $30 \%$ RCA in place of natural aggregate were evaluated. The Marshall mix design procedure was used to develop the mixes. To improve the moisture sensitivity of the mixes, they were cured in an oven for 4 hours. The results indicated that the mixes comply with Spanish moisture damage specifications. The mechanical properties (stiffness, permanent deformation and fatigue) of the mixtures were studied. The mixtures exhibited good engineering properties. Although HMA with RCA requires further investigation, the results from this study were very promising.

Keywords: hot-mix asphalt, recycled concrete aggregate, mechanical properties

\section{Introduction}

Concerns in recent decades about achieving sustainable growth has resulted in attempts to recycle or reuse a large portion of construction waste materials. This is the case for recycled concrete aggregate (RCA) from construction and demolition waste (CDW). Its use has been growing in recent years, particularly as aggregate for concrete [1-2] and unbound pavement layers [3-5]. However, further research is needed to diversify RCA applications and make its use a habitual practice.
\end{abstract}

Although RCA is most likely suitable for use as aggregate in hot-mix asphalt (HMA) for pavements in road building, to date only a few studies have been carried out dealing with the use of this type of waste material in HMA [6-23]. 
Many researchers have noted that the attached mortar (figure 1a), which is more porous and less dense than crushed stone, seems to be the principal reason for RCA being of unsatisfactory quality $[6,10-12,14,22-24]$, but it is not the only reason. In fact, some studies have recommended removing impurities such as wood, rubber, gypsum, etc. with the aim of making RCA more homogeneous $[6,10,11,21,23]$. The tiny fissures that appear during the crushing process [12] and the weak contact between the mortar and aggregate [22] are other factors to take into account. All of these reasons make RCA from $\mathrm{CDW}$ a poorer-quality aggregate than natural aggregate $[22,24]$. Obviously, differences between the properties of RCA and those of natural aggregates are going to influence the performance of HMA made with RCA. It is also expected that the RCA content (between $0 \%$ and 100\%) will affect HMA performance.

It is particularly interesting to note that some studies have indicated that HMA mixes made with RCA have higher moisture sensitivity than those made with natural aggregates only $[10,11,15$, 21, 23]. Moisture sensitivity or moisture damage is a deterioration process that affects HMA and is defined as the degradation of mechanical properties of the mixture due to the presence of water [25]. There are many ways to improve the moisture sensitivity of conventional HMA, including the use of antistripping additives, the addition of selected fillers, avoidance of hydrophilic aggregates, etc. [26]. Previous research conducted with the same RCA used in this investigation $[18,21,23]$ recommended allowing the HMA sufficient time at high temperature to complete the binder absorption by the aggregates. This could be a way to improve the moisture sensitivity of HMA made with RCA, since the bitumen absorbed by RCA makes the whole aggregate surface be coated by the binder, leaving no fissures through which water could penetrate. Furthermore, it reduces the porosity decreasing at the same time water accessible voids.

Moisture sensitivity is not the only HMA property that could be affected by the use of CDW as recycled aggregate. Some researchers have stated that the use of RCA in HMA production leads to mixes with less stiffness than conventional mixes [10,15], while others suggest the opposite $[8,11]$. The literature on the permanent deformation of HMA made with RCA yields varied 
conclusions. Most researchers consider mixtures made with RCA to comply with specifications related to permanent deformation $[9,11,15,18,21,23]$ and exhibit permanent deformation behaviour similar to conventional mixes $[10]$ or better $[7,8,13,20]$. However, other researchers indicate that despite meeting the specifications, permanent deformation performance worsens as the percentage of RCA in the mix increases [15]. Others indicate that permanent deformation performance is also influenced by the mixture gradation [14]. The fatigue life of HMA containing RCA has been studied less. The studies to date indicate that HMA with RCA are similar in fatigue life to conventional mixtures $[11,17]$. There is one exception: when RCA is used as filler, fatigue life improves [20].

This paper presents an investigation of the mechanical properties of HMA made with RCA from CDW for base courses. The aim of the investigation is to design HMA with RCA and achieve good mechanical properties and good moisture sensitivity performance. Following the example of previous studies $[18,21,23]$, to improve the moisture sensitivity of the asphalt mixes used, they were cured in an oven at the mixing temperature for 4 hours after mixing and before compaction. This made it possible for, the aggregate, particularly the RCA, to absorb a greater amount of bitumen. Not only improved mortar resistance but also less water absorption, and thus better moisture damage performance, is expected as a result. The moisture sensitivity, stiffness, permanent deformation and fatigue life of HMA mixes containing RCA were studied.

\section{Materials and methods}

\subsection{Basic materials}

\subsubsection{Aggregates}

Two types of aggregates were used: RCA and natural aggregate. RCA was obtained from demolition waste from residential buildings of different origins and qualities in Madrid (Spain) and was supplied by a CDW recycling plant. Aggregate, concrete, and similar materials constituted $89.3 \%$ of the mass of the RCA obtained for use in this study, and bituminous materials constituted $6.5 \%$. The remainder of the constituents were impurities (ceramics, wood, rubber, gypsums, etc.) that could introduce variation in the test results. Gypsum (figure 1b) is an 
impurity that is polishable and has a poor affinity with bitumen, so it would be wise to remove it before using RCA in HMA production. The natural aggregate used was a hornfels that was supplied by a local contractor and is typically used in HMA production in Spain. The compositions of the natural and recycled aggregates were determined using X-ray fluorescence tests. The results indicated that the RCA $\left(61.46 \% \mathrm{SiO}_{2}\right)$ and hornfels $\left(62.30 \% \mathrm{SiO}_{2}\right)$ are siliceous aggregates. Consequently, both of them were expected to exhibit poor stripping performance.

The RCA and natural aggregate properties were evaluated according to the Spanish General Technical Specifications for Roads, also known as PG-3 [27]. The results (shown in table 1) indicate that the RCA had a lower bulk specific gravity ( $\rho$ a) than the natural aggregate as well as a higher water absorption $\left(\mathrm{W}_{24}\right)$. This is due to the mortar on the RCA surface. The sand equivalent (SE) values of the RCA and the natural aggregate complied with the PG-3 for HMA as a base course material. The RCA's Los Angeles (LA) abrasion coefficient only complied with the PG-3 for HMA as a base course material in low-volume roads in heavy traffic category T4. The LA abrasion coefficient of the hornfels aggregate complied with the PG-3 for HMA as a base course material in roads in heavy traffic category T00. The LA abrasion coefficient of a mix of RCA and natural aggregate was also determined. The results showed that for mixes of $0 \%, 5 \%, 10 \%, 20 \%$ and $30 \%$ replacement of natural aggregate by RCA, the combined (RCA + natural) LA abrasion coefficient complied with the PG-3 (LA<25\%) for HMA as a base course material in roads in heavy traffic category $\mathrm{T} 00$.

\subsubsection{Binder and filler}

A B50/70 binder from Venezuela was chosen for use in this study. Its engineering properties are presented in table 2. Grey Portland cement (CEM II/B-M (V-L) $32.5 \mathrm{~N}$ ) was obtained from a commercial source for use as mineral filler. Its Blaine surface area was equal to $3,134 \mathrm{~cm}^{2} / \mathrm{g}$ and its specific gravity was equal to $3.10 \mathrm{~g} / \mathrm{cm}^{3}$.

\subsection{Testing program}

\subsubsection{Marshall mix design}


The Marshall mix design procedure, as specified in NLT-159/86 [28], was used in this investigation. The laboratory mixing temperature was $170^{\circ} \mathrm{C}$ and the compaction temperature was $165^{\circ} \mathrm{C}$. Percentages of $0 \%, 5 \%, 10 \%, 20 \%$ and $30 \%$ of RCA by weight of total aggregate were studied. The aggregate gradation, an AC 22 base G (figure 2), was chosen in accordance with the PG-3. The aggregate gradation had a maximum aggregate size of $22 \mathrm{~mm}$ and a $4 \%$ mineral filler content. It is important to take into account that RCA fine fraction is more sensitive to adhesion phenomena and exhibits greater water absorption. Furthermore, the smaller the size of RCA particles is, the higher the content of mortar cement is, which negatively affects the properties of RCA [24]. Also, it is more difficult to remove impurities in the fine fraction. For these reasons, to manufacture HMA, it was considered more suitable to make the replacement of RCA in the coarse fractions $8 / 16 \mathrm{~mm}$ (RCA replacement of $5 \%, 10 \%$, $20 \%$ and $30 \%$ ) and $4 / 8 \mathrm{~mm}$ (RCA replacement of $30 \%$ ). Substitution at larger fractions could introduce greater dispersions in the results due to the heterogeneity of the material. After mixing, the loose mixtures were cured in an oven at $170^{\circ} \mathrm{C}$ for 4 hours. Cylindrical specimens $101.6 \mathrm{~mm}$ in diameter and $63.5 \mathrm{~mm}$ in height were formed using the Marshall compactor (with 75 blows on each side). In order to determine the optimum asphalt content (Bo), the bitumen percentage was selected, inside limits, that allow to achieve the maximum Marshall stability and thus, the highest traffic category possible. Also, flow (F), air voids (Va) and voids in the mineral aggregate (VMA) were selected in accordance with the PG-3 specifications. RCA is a porous aggregate, so it is interesting to determine not only the optimum asphalt content but the effective binder content $(\mathrm{Pbe})$ and the absorbed bitumen content $(\mathrm{Pba})$ [29].

\subsubsection{Moisture damage}

UNE-EN 12697-12 [30] was used to evaluate the moisture sensitivity (stripping potential) of HMA made with RCA by measuring the loss of indirect tensile strength, expressed in terms of the tensile strength ratio (TSR). In this test, a set of cylindrical samples is subdivided into two subsets with the same number of specimens in each subset. One subset was kept dry at room temperature, while the other subset was saturated and was held in a water bath for 3 days at 
$40^{\circ} \mathrm{C}$. After that time, the two subsets were left a minimum of 2 hours at $15^{\circ} \mathrm{C}$, the dry specimens in air and the wet specimens in water. The tensile strength of the specimens in each subset was then determined.

Five sets $(0 \%, 5 \%, 10 \%, 20 \%$ and $30 \%$ RCA) of ten samples each were evaluated. The samples were produced at the optimum bitumen content for each RCA percentage. The specimens were left in an oven at $170^{\circ} \mathrm{C}$ for 4 hours after mixing. Marshall specimens were formed (with 50 blows on each side). Moisture sensitivity was evaluated as follows:

$\mathrm{TSR}=\frac{\mathrm{ITS}_{\mathrm{w}}}{\mathrm{ITS}_{\mathrm{D}}} \times 100$

where TSR $=$ the tensile strength ratio $(\%), \mathrm{ITS}_{\mathrm{W}}=$ the average tensile strength of five conditioned (wet) specimens $(\mathrm{MPa})$ and $\mathrm{ITS}_{\mathrm{D}}=$ the average tensile strength of five unconditioned (dry) specimens (MPa). TSR $\geq 80 \%$ is required by PG-3 specifications [27] for HMA for use in base courses.

\subsubsection{Stiffness}

The indirect tensile stiffness modulus test (ITSM) was used to determine the resilient modulus of the HMA mixes in accordance with UNE-EN 12697-26 Annex C [31], using a Cooper NU 14 tester. In each test, ten conditioning haversine pulses were applied along the vertical diameter of a cylindrical specimen. Afterward, five haversine test pulses were applied. The repetition period of the impulse was $3 \pm 0.1$ seconds. The maximum load was selected to achieve a maximum horizontal strain of $0.005 \%$ of the specimen diameter. The rise time was $124 \pm 4 \mathrm{~ms}$. The average stiffness modulus of a specimen was determined from the five test pulses. After rotating the specimen $90^{\circ}$, the test sequence was repeated. The average stiffness from the two tested diameters was recorded as the stiffness modulus of the HMA specimen.

The specimens were cured in an oven at $170^{\circ} \mathrm{C}$ for 4 hours before compaction. Marshall specimens were formed (at 75 blows on each side) at the optimum binder content for each RCA percentage. The indirect tensile modulus of the specimens was tested in a controlledtemperature cabinet at temperatures of $0^{\circ} \mathrm{C}, 10^{\circ} \mathrm{C}$ and $20^{\circ} \mathrm{C}$. 
The resilient modulus was determined using the following equation:

$M_{R}=\frac{F \times(v+0.27)}{Z \times h}$

where $\mathrm{M}_{\mathrm{R}}=$ the resilient modulus $(\mathrm{MPa}), \mathrm{F}=$ the maximum applied load $(\mathrm{N}), \mathrm{z}=$ the horizontal deformation $(\mathrm{mm}), \mathrm{h}=$ the sample thickness $(\mathrm{mm})$ and $v=$ Poisson's ratio (a Poisson's ratio of 0.35 was assumed for the HMA mixes for all of the test temperatures).

Spanish specifications [27] require a minimum resilient modulus of $11,000 \mathrm{MPa}$ at $20^{\circ} \mathrm{C}$ in the case of high-modulus HMA. However, there are no requirements for conventional mixtures.

\subsubsection{Permanent deformation}

To evaluate the resistance of the mixes to permanent deformation, repeated-load axial testing (RLAT) without confinement was conducted, in accordance with DD 226:1996 [32], using a Cooper NU 14 tester. In the test, axial square pulses are applied to cylindrical samples. The same Marshall specimens used in the resilient modulus tests were used in the repeated-load axial tests. Each specimen was held at a test temperature of $30^{\circ} \mathrm{C}$ in a controlled-temperature cabinet overnight and then was placed between two load platens. A preload of $10 \mathrm{kPa}$ of axial stress was applied for $600 \pm 6 \mathrm{~s}$. The sample was then subjected to 1,800 load applications. These tests were performed under the following load conditions: an axial stress of $100 \pm 2 \mathrm{kPa}$, a load application period of $1 \mathrm{~s}$ and a rest period of $1 \mathrm{~s}$. The following equation was used to calculate the axial permanent strain:

$$
\varepsilon_{d(n, T)}=\frac{\Delta h}{h_{0}}
$$

where $\varepsilon_{\mathrm{d}(\mathrm{n}, \mathrm{T})}=$ the axial permanent strain (in $\mu \varepsilon$ ) after $\mathrm{n}$ load applications at temperature $\mathrm{T}$ in ${ }^{\circ} \mathrm{C}$, $\mathrm{h}_{0}=$ the initial distance between the two load platens $(\mathrm{mm})$ and $\mathrm{h}=$ the axial deformation $(\mathrm{mm})$.

\subsubsection{Fatigue}


Fatigue life was evaluated using the repeated indirect tensile fatigue test (ITFT), in accordance with UNE-EN 12697-24 Annex E [33], using a Cooper NU 14 tester. This is a controlled-stress fatigue test in which cylindrical specimens are subjected to repeated haversine loads along a vertical diameter. Controlled-stress tests are adequate to evaluate the fatigue life of thick bituminous pavement layers with high stiffnesses [34]. Marshall specimens at the optimum bitumen content were compacted at 75 blows per side after 4 hours in an oven. For every RCA content, a minimum of three specimens were tested at each of three constant tension levels (350 $\mathrm{kPa}, 450 \mathrm{kPa}$ and $550 \mathrm{kPa}$ were chosen). The tests were conducted at a reference temperature of $20^{\circ} \mathrm{C}$ in a controlled-temperature cabinet. The Whöler equation was used to obtain regression equations for fatigue life:

$\varepsilon_{0}=k \cdot N f^{-n}$

where $\mathrm{Nf}=$ the number of load cycles to fatigue failure, $\mathrm{k}$ and $\mathrm{n}=$ material constants obtained from the ITFT and $\varepsilon_{0}=$ the initial tensile horizontal strain at the centre of the specimen in $\mu \varepsilon$. A combination of permanent deformation and fatigue mechanisms occur during the ITFT [35]. Thus, two failure criteria were used to determine the fatigue life of a specimen: the total number of load cycles to complete splitting of the specimen along the vertical plane or the total number of cycles to $10 \%$ vertical deformation of the specimen along the vertical plane, whichever came first.

\section{Test results and discussion}

\subsection{Marshall mix design}

The optimum asphalt content (Bo), effective binder content ( $\mathrm{Pbe}$ ) and bitumen absorption content (Pba) of the HMA mixes are shown in table 3, along with other mix properties, such as the unit weight (UW), air voids (Va), voids in the mineral aggregate with and without consideration of binder absorption $\left(\mathrm{VMA}_{\mathrm{abs}}\right.$ and VMA, respectively), voids filled with asphalt with and without considering binder absorption $\left(\mathrm{VFA}_{\mathrm{abs}}\right.$ and VFA, respectively), stability (S) and flow (F). 
As table 3 shows, a general pattern exists among the Bo, Pba, Pbe and RCA contents: Bo and Pba increase with increasing RCA content, while Pbe decreases. On the one hand, this indicates that the porosity of the mortar attached to the RCA makes the RCA absorb binder in proportion to the percentage of RCA in the HMA. Thus, HMA containing RCA requires more binder as the RCA content increases. On the other hand, the decreasing trend in Pbe with increasing RCA indicates that the bitumen film thickness decreases with increasing RCA content, which could affect HMA performance, especially for high RCA contents. However, there are exceptions to this general pattern. For example, $20 \%$ RCA is an exception to this trend. It could be explained by the heterogeneity of RCA used in this investigation. As said before, the RCA used in this investigation was obtained from the demolition of residential buildings, hence, it has particles of other materials such as gypsum, wood, asphalt, etc. Moreover, it has concrete from different origins and thus, with different qualities.

As was expected and table 3 shows, UW decreases as RCA increases. This is because RCA is less dense than natural aggregate. Furthermore, the results show that Va exhibits a slight increase as the RCA content increases. Va is determined as a function of unit weight, so a decrease in UW leads to an increase in Va. However, an increase in Va can be explained by the difficulty of compacting HMA containing RCA, due to the roughness of the attached mortar. The results in table 3 also show that when asphalt absorption is not considered, VMA increases slightly as the RCA percentage increases. This result is obvious because Bo increases as well, and not considering asphalt absorption implies that all of the bitumen is part of VMA. In contrast, if asphalt absorption is considered, $\mathrm{VMA}_{\mathrm{abs}}$ decreases slightly as the RCA percentage increases. This means that an increase in RCA content produces greater asphalt absorption. The values obtained for VMA indicate that not considering asphalt absorption overestimates this parameter. When using RCA in HMA, this consideration could be of great importance, particularly if a high percentage of RCA is used.

As shown in Table 3, according to PG-3, all the samples tested contain air voids and voids in mineral aggregate suited to meet a heavy traffic category $\mathrm{T} 00[27,36]$. 
Table 3 shows that the same occurs with VFA: not considering asphalt absorption overestimates VFA. If absorbed bitumen is taken into account, $\mathrm{VFA}_{\mathrm{abs}}$ decreases as the RCA content increases, reflecting the absorptivity of RCA.

The stability $(\mathrm{S})$ values are very high: greater than $15 \mathrm{kN}$ in all cases. This means that HMA made with RCA in percentages ranging from $0 \%$ to $30 \%$ comply with PG-3 specifications for traffic category T00 [36].

Most of the results indicate an increasing trend in flow (F) as the RCA percentage increases. Thus, it can be concluded that an increase in RCA content produces mixtures that are more susceptible to deformation. However, it should be noticed that $\mathrm{F}$ values are inside the range specified for traffic category T00 by the PG-3 [36].

The Marshall S/F ratio may be used as an indicator of stiffness: mixtures with high S/F ratios are more resistant to permanent deformation. Although it can be observed that the S/F ratios obtained do not follow a clearly defined pattern, it seems that increasing the RCA content decreases the $\mathrm{S} / \mathrm{F}$ ratio, so a general conclusion can be drawn that mixtures with higher RCA content will perform worse in terms of permanent deformation.

\subsection{Moisture damage}

The results of the moisture sensitivity tests for samples made with optimum binder content are shown in figure 3. On the one hand, as the results show, a certain pattern exists: in general, ITS decreases as RCA increases. This is true in both the dry and wet states. There is only one exception: the samples with $5 \%$ of RCA did not follow this trend. This exception could be explained by the heterogeneity characteristics of the RCA used. On the other hand, all of the TSR values obtained were greater than $80 \%$, which is the requirement established in the Spanish specifications for HMA in base courses. However, it is surprising that the worst TSR value was measured for an RCA percentage of $0 \%$. This suggests that although the moisture sensitivity of RCA is not good, it is better than the moisture sensitivity of the natural aggregate used. This is consistent with the results obtained from the X-ray fluorescence tests: as the $\mathrm{SiO}_{2}$ percentage increases, the stripping performance worsens. As mentioned previously, the literature review indicates different results for the stripping performance of HMA made with RCA. This 
discrepancy can be explained by the fact that the stripping performance of HMA made with RCA depends not only on the type of RCA used (origin, impurities, crushing process, etc.) but also on the affinity of the natural aggregate used with bitumen.

A two-way analysis of variance (ANOVA) was conducted to determine the effect of RCA percentage $(0 \%, 5 \%, 10 \%, 20 \%$ and $30 \%)$ and state (dry or wet) on indirect tensile strength (ITS). The model explains $89.88 \%$ of the total variance. The RCA percentage is statistically significant at the $95 \%$ confidence level $(p=0.039<0.05)$. The other main effect, i.e., dry or wet state, is not significant $(\mathrm{p}=0.221)$. On the basis of the ANOVA, it can be deduced that the most influential factor in ITS is the RCA percentage. That the wet or dry state is not statistically significant means that the applied treatment reduces the effect of water on the indirect tensile strength. It should be noted that at 5\% RCA, the wet strength is higher than the dry strength. A one-way ANOVA was conducted to determine the effect of RCA percentage $(0 \%, 5 \%, 10 \%$, $20 \%$ and $30 \%$ ) on the tensile strength ratio (TSR). The ANOVA results indicate that the RCA percentage has a significant effect on TSR $(\mathrm{p}=0.000)$. Thus, a variation in the RCA content will influence the stripping performance of HMA.

\subsection{Stiffness}

As stated previously, there are no Spanish specifications for the acceptance of conventional mixtures in terms of resilient modulus $\left(\mathrm{M}_{\mathrm{R}}\right)$, so it is useful to compare the resilient modulus results obtained for the different mixtures tested in this investigation. The only PG-3 specification concerning resilient modulus is that high-modulus HMA must have a minimum resilient modulus of $11,000 \mathrm{MPa}$ at $20^{\circ} \mathrm{C}$. As figure 4 shows, the HMA mixtures produced with optimum binder content and with $10 \%$ to $30 \%$ RCA almost satisfy the 11,000 MPa requirement that would classify them as high-modulus HMA mixtures.

Thus, despite HMA mixtures made with RCA not meeting the requirement to be classified as high-modulus HMA mixtures, they are nonetheless very stiff mixtures. High-resilient-modulus mixtures are stiffer and have longer fatigue lives when they are used in thick layers [33]. However, at low temperatures, high-resilient-modulus mixtures are more susceptible to thermal and fatigue cracking [36]. Thus, mixtures used in surface courses with elastic moduli above 
$3,100 \mathrm{MPa}$ at $20^{\circ} \mathrm{C}$ must be used with caution in cold regions [36]. As figure 4 shows, all the mixtures tested in this investigation had resilient modulus values much higher than $3,100 \mathrm{MPa}$ at $20^{\circ} \mathrm{C}$. Although the mixes studied are intended for use in base courses and not surface courses, the results indicate that HMA with RCA is suitable for surface course use in temperate regions. However, the high stiffness values obtained confirm that the mixtures can be used in thinner layers while maintaining their structural integrity [15] if they are used in temperate regions. HMA used in Spain has a typical mean resilient modulus of 5,000 MPa at $20^{\circ} \mathrm{C}$ [37]. The resilient modulus values of the mixes studied were higher than 5,000 MPa, which indicates that the studied mixtures are stiffer than conventional mixtures. Figure 4 shows that the resilient modulus of HMA made with RCA is strongly dependent on the test temperature. As expected, the mixtures were stiffer at lower temperatures. In Spain, a winter resilient modulus 1.5 times higher than the mean value is often adopted [37]. The resilient modulus of HMA with RCA $0^{\circ} \mathrm{C}$ is 2.1 to 4.9 times higher than that at $20^{\circ} \mathrm{C}$, while at $10^{\circ} \mathrm{C}$, the resilient modulus is 1.5 to 3.7 times higher. Therefore, the resilient modulus of HMA made with RCA exhibits much more dependence on in-service temperatures than conventional mixtures. Moreover, there is no clear pattern between RCA content and resilient modulus, due to the heterogeneity of the RCA used.

Only at $20^{\circ} \mathrm{C}$ does the resilient modulus seem to increase with increasing RCA content.

However, this is only true for RCA contents up to $20 \%$.

A two-way ANOVA was conducted to determine the effect of RCA percentage $(0 \%, 5 \%, 10 \%$, $20 \%$ and $30 \%)$ and test temperature $\left(0^{\circ} \mathrm{C}, 10^{\circ} \mathrm{C}\right.$ and $\left.20^{\circ} \mathrm{C}\right)$ on stiffness $\left(\mathrm{M}_{\mathrm{R}}\right)$. The model explains $97.85 \%$ of the total variance. The test temperature is statistically significant at the $95 \%$ confidence level $(\mathrm{p}=0.000<0.05)$. As expected in view of the test results obtained, the ANOVA confirms that the other main effect, RCA percentage, is not significant $(p=0.0759)$. On the basis of the ANOVA, it can be deduced that the dominant factor in specimen stiffness is test temperature.

\subsection{Permanent deformation}

Results of the permanent deformation tests indicate the rutting potential of the mixtures. Figure 5 shows the accumulated permanent deformation values versus the number of loading cycles. 
As expected, permanent deformation increases with the number of cycles for mixtures made with the optimum binder content. There is no clear pattern between the final permanent deformation at cycle 1,800 and the RCA percentage. It could be explained by the heterogeneity of the RCA used in this investigation. It is well known that HMA permanent deformation occurs mainly due to densification (a decrease in the air void content causing a volume change) and plastic flow (aggregates and binder being gradually moved without a volume change) [38]. The test results indicate that permanent deformation of HMA made with RCA occurs mainly due to densification. Plastic flow did not occur, so the specimens did not fail during the tests. Figure 5 also shows that after a given number of load applications, a linear relationship exists between the axial permanent strain and the number of load cycles. The slope of the line reflects the trend of axial deformation, such that larger slopes indicate less resistance to permanent deformation [39]. As table 4 shows, the slopes of the lines between cycles 600 and 1,800 are very similar, but indicate a certain pattern between RCA content and permanent deformation: in general, when RCA content increases, so does permanent deformation. However, the $30 \%$ RCA mix did not follow this pattern. At the beginning of the load cycling, the mixtures exhibit rapid densification. Although the slopes are very similar for all the tested percentages of RCA, the different amounts of this rapid initial densification in the different mixes are largely responsible for the differences in the final permanent deformation at 1,800 load cycles. It is expected that higher bitumen contents produce mixtures with greater susceptibility to plastic deformation [7]. In the case of HMA made with RCA, as the RCA content increases, the effective bitumen content decreases, so the increase in the permanent deformation slope is mainly due to the increase in RCA content. These results are consistent with the Marshall S/F ratio results. For all of the RCA percentages tested, the HMA mixtures exhibited ultimate permanent deformation levels lower than those that conventional mixtures exhibit. For example, Santagata et al. [40] obtained values of the final strain between 4,000 and $11,000 \mu \varepsilon$ at 1,800 load cycles for HMA made with various binders, while Aschuri et al. [41] obtained values of approximately 13,000 $\mu \varepsilon$ for conventional mixtures. As figure 5 shows, all of the studied mixtures had final axial 
permanent strain values lower than $11,000 \mu \varepsilon$ at 1,800 cycles. Thus, mixtures with RCA that have been oven-cured for 4 hours will perform well against rutting.

A one-way ANOVA was conducted to determine the effect of RCA content on permanent deformation at 1,800 load cycles. The ANOVA results show that the RCA content has a significant effect on permanent deformation $(\mathrm{p}=0.000)$.

\subsection{Fatigue}

As stated previously, the ITFT is suitable for high-stiffness mixtures used in thick layers. Thus, it is a suitable test for simulating the fatigue performance of the high-resilient-modulus mixtures examined in this investigation.

A fatigue test ends when a sample is fractured by a diametral plane and split into two parts.

None of the tested specimens failed in terms of the alternate criterion, a vertical deformation of $10 \%$ of the specimen diameter. Therefore, it can be concluded that fatigue mechanisms were predominant in the failure of all the HMA samples tested (figure 6).

Figure 7 shows the initial horizontal strain versus the number of cycles to failure at $20^{\circ} \mathrm{C}$ on a logarithmic scale for the mixtures made with the optimum asphalt content. The same figure shows the fatigue equations of the tested mixtures. It is interesting to note that mixtures with low RCA percentages (up to $20 \%$ ) perform similarly to each other in fatigue, especially at high deformation levels, while the fatigue performance of HMA with $30 \% \mathrm{RCA}$ is a little poorer. This is highlighted by the fact that the fatigue equation for this mixture has a much more pronounced slope than the other fatigue equations. However, the coefficients of determination $\left(\mathrm{R}^{2}\right)$ vary a great deal for the different fatigue equations, which might be due to the heterogeneity of the RCA.

A fatigue equation for the control mixture ( $0 \% \mathrm{RCA}$ and without curing oven time) has been plotted for comparison with the fatigue equations obtained for the mixes tested in this study. In general, HMA made with RCA that has been left in the oven for 4 hours exhibits similar fatigue life to control mixture, except the mixture made with $30 \%$ RCA that has a fatigue resistance slightly slower than conventional. Moreover, the slopes of the equations for the mixes with RCA percentages between $0 \%$ and $20 \%$ are flatter than the slopes of the equations for the 
control mixture, indicating that HMA containing up to $20 \%$ RCA has a greater fatigue life than conventional mixtures at higher number of cycles. For HMA containing 30\% RCA, the slope of the fatigue equation is similar to that of the conventional mixture.

\section{Final remarks}

The results of the tests conducted in this investigation are encouraging. Bituminous mixtures made with RCA from CDW were shown to exhibit good moisture sensitivity and more than acceptable mechanical properties. With adequate pretreatment and with a limited RCA content, HMA made with RCA can be used in warm regions. The mixtures should be oven-cured for 4 hours before compaction, and a maximum of $30 \%$ of RCA appears to be adequate.

The use of HMA made with RCA promotes sustainable construction by providing numerous environmental benefits, such as reduced extraction of natural aggregates from quarries, avoidance of the visual impact of landfills, avoidance of rejection of raw materials, etc. However, there are some disadvantages to the use of RCA in HMA. The cost of removal of impurities (e.g., gypsum) is one disadvantage. There are also environmental disadvantages, such as an increase in bitumen consumption with increasing RCA content and the associated increase in energy consumption. Limiting the RCA content to $30 \%$ produces a maximum increase of $0.5 \%$ in the bitumen content, which is an acceptable value. Further investigation is needed to implement a storage system in asphalt plants that maintains the temperature of such mixtures without increased consumption of fossil fuels.

\section{Conclusions}

HMA made with $0 \%, 5 \%, 10 \%, 20 \%$ and $30 \% \mathrm{RCA}$ in the $4 / 8 \mathrm{~mm}$ and/or $8 / 16 \mathrm{~mm}$ coarse fractions of the aggregate gradation have been studied. To improve their moisture sensitivity, the mixtures were oven-cured for 4 hours after mixing and before compaction at $170^{\circ} \mathrm{C}$. The following conclusions are drawn from this research:

- RCA has a high LA abrasion coefficient, which is a weakness of HMA made with RCA. However, combined with suitable natural aggregate in suitable proportions, RCA can be used to produce an HMA mix with acceptable abrasion resistance. 
- Asphalt absorption is another property of RCA that must be taken into account. In general, the optimum asphalt content and bitumen absorption of HMA made with RCA increases with increasing RCA content, while the effective binder content decreases slightly. This is due to the absorptivity of the attached mortar on the surface of RCA. As a consequence, as the RCA content increases, more binder is needed. In addition, as the effective binder content decreases, so does the thickness of the binder film, so it is particularly important to limit the RCA content in HMA production.

- Asphalt absorption is an important parameter influencing the volumetric properties of HMA made with RCA. Not considering asphalt absorption leads to overestimating VFA and VMA. The differences between the volumetric properties determined considering asphalt absorption versus not considering it become more pronounced as the RCA content increases, which is another reason to limit the RCA content.

- HMA made with RCA exhibits high Marshall stability values, but the indirect tensile strength decreases with RCA content, so the RCA content must be limited.

- Moisture damage is a key concern. The RCA content has been demonstrated to be an important factor in the stripping performance of HMA made with RCA. The moisture susceptibility of HMA made with RCA may be better or worse than conventional HMA, depending on the natural aggregate with which the RCA is combined.

- The tested mixtures exhibited very good stripping performance. HMA mixes made with RCA and oven-cured for 4 hours before compaction comply with Spanish specifications for use in pavement base courses in road construction.

- The tested HMA mixtures containing RCA exhibited very high stiffness and a strong dependence on temperature. Such mixtures should not be used in cold regions.

- Although the RCA content seems to have no influence on the stiffness of the mixture, at $20^{\circ} \mathrm{C}$, the results indicate that an increase in the recycled aggregate content slightly stiffens the mixture, although these particular results were not statistically significant. 
- Although the permanent deformation test results indicate that HMA with up to $30 \%$

RCA exhibit good rutting performance, permanent deformation increases with

increasing RCA content, so mixtures with higher RCA percentages should be expected

to be more susceptible to deformation.

- The fatigue life of HMA made with RCA is satisfactory. In particular, mixes with up to $20 \%$ RCA exhibit similar fatigue life to conventional mixture. For mixture made with $30 \%$ RCA fatigue life is slightly slower than for conventional mixture.

- Although the results of this investigation are encouraging, HMA made with RCA requires further investigation, particularly to assess its performance in the field. It is also necessary to determine the maximum percentage of RCA that can be used in HMA.

\section{Acknowledgments}

The authors wish to acknowledge the Spanish Ministry of Education and Science for sponsoring this research through Project BIA2010-17751.

The authors would like to thank Nynas Bitumen for supplying the binder used in this study.

\section{References}

[1]. B. González-Fonteboa, F. Martínez-Abella. "Recycled aggregates concrete: aggregate and mix properties". Mater Construcc 2005; 55 (279): 53 - 66.

[2]. Wai Hoe Kwan, Mahyudin Ramli, Kenn Jhun Kam, Mohd Zailan Sulieman. "Influence of the amount of recycled coarse aggregate in concrete design and durability properties". Constr Build Mater 2012; 26: 565 - 573.

[3]. Poon Chi Sun, Chan Dixon. "Feasible use of recycled concrete aggregates and crushed clay brick as unbound road sub-base". Constr Build Mater 2006; 20: 578 - 585.

[4]. NCHRP. Report 598. Performance-Related Test of Recycle Aggregates for Use in Unbound Pavement Layers. Transportation Research Board; 2008.

[5]. Vegas I., Ibáñez J.A., Lisbona A., Sáez de Cortazar A., Frías M. "Pre-normative research on the use of mixed recycled aggregates in unbound road sections". Constr Build Mater 2011; 25: 2674 2682.

[6]. Cupo-Pagano M., D’Andrea A., Giavarini C., Marro C. "Use of building demolition waste for asphalt mixes: first results". Energy, environment and technological innovation. Proceedings of III International Congress; 1994; p. 203 - 208.

[7]. Shen D., Du J. "Evaluation of building materials recycling on HMA permanent deformation". Constr Build Mater 2004; 18: 391 - 397.

[8]. Shen D., Du J. "Application of Gray Rational Analysis to Evaluate HMA with Reclaimed Building Materials". J Mater Civil Eng 2005; 17: 400 - 406.

[9]. Aljassar A.H., Al-Fadala K.B. "Recycling building demolition waste in hot-mix asphalt concrete: a case study in Kuwait". J Mater Cycles Waste 2005; 7: 112 - 115.

[10]. Paranavithana Sumeda, Mohajerani Abbas. "Effects of recycled concrete aggregates on properties of asphalt concrete" Resour Conserv Recy 2006; 48: 1 - 12. 
[11]. Pérez I., Toledano M., Galego J., Taibo J. "Mechanical properties of hot mix asphalt made with recycled aggregates from reclaimed construction and demolition debris". Mater Construcc 2007; 57 (285): $17-29$.

[12]. Tam Vivian W.Y., Tam C.M., Le K.N. ’Removal of cement mortar remains from recycled concrete aggregate using pre-soaking approaches". Resour Conserv Recy 2007; 50: 82 - 101.

[13]. Wong Y.D., Sun D.D., Lai D. "Value-added utilisation of recycled concrete in hot-mix asphalt". Waste Manage 2007; 27: 294 - 301.

[14]. Gul Waqar Ahmed. Effect of Recycled cement concrete content on rutting behaviour of asphalt concrete. Doctoral Thesis. Middle East Technical University. Ankara; 2008.

[15]. Mills-Beale J., You Z. "The mechanical properties of asphalt mixtures with recycled concrete aggregates". Constr Build Mater 2010; 24: 340 - 345.

[16]. Mukhopadhyay Anol K., Geiger Brian J., Button Joe. "Use of Alkali-Silica Reaction-Affected Recycled Concrete Aggregate in Hot-Mix Asphalt”. Transportation Research Record. Journal of the Transportation Research Board 2010; 2179: 1 - 9.

[17]. Pérez I., Gallego J., Toledano M., Taibo, J. “Asphalt mixtures with construction and demolition debris". Proceedings of the Institution of Civil Engineers. Transport 2010; 163: 165 - 174.

[18]. Pérez I., Pasandín A.R., Gallego J. "Impact of Construction and Demolition Waste Aggregates on Stripping in Hot-Mix Asphalt. Presented at 89th Annual Meeting of the Transportation Research Board, Washington, D.C.; 2010.

[19]. Bhusal Sushanta, Li Xiaojun, Wen Haifang. "Evaluation of Effects of Recycled Concrete Aggregate on Volumetrics of Hot-Mix Asphalt. Transport Res Rec. Journal of the Transportation Research Board 2011; 2205 (3): 36 - 39.

[20]. Chen Meizhu, Lin Juntao, Wu Shaopeng. "Potential of recycled fine aggregates powder as filler in asphalt mixture". Constr Build Mater 2011; 25: 3909 - 3914.

[21]. Pérez I., Pasandín A.R and Gallego J. "Stripping in hot mix asphalt produced by aggregates from construction and demolition waste". Waste Manage Res 2012; 30 (1): 3 - 11.

[22]. Lee Cheng-Hsiao, Du Jia-Chong, Shen Der-Hsien. "Evaluation of pre-coated recycled concrete aggregate for hot mix asphalt". Constr Build Mater 2012; 28: 66 - 71.

[23]. Pérez I., Pasandín A.R, Medina L. "Hot mix asphalt using C\&D waste as coarse aggregates". Mater Design 2012; 36: 840-846.

[24]. Sánchez de Juan Marta, Alaejos Gutiérrez Pilar. "Study on the influence of attached mortar content on the properties of recycled concrete aggregate". Constr Build Mater 2009; 23: 872 - 877.

[25]. Caro S., Masad E., Bhasin A., Little D.N. "Moisture susceptibility of asphalt mixtures, Part 1: mechanisms". Int J Pavement Eng 2008; 9 (2): 81 - 88.

[26]. Abo-Qudais Saad, Walid Mulqi Mohammad. "New Chemical Antistripping Additives for Bituminous Mixtures". Journal of ASTM International 2005; 2 (8): 1-11.

[27]. MINISTERIO DE FOMENTO. O.C. 24/08 sobre el Pliego de Prescripciones Técnicas Generales para obras de carreteras y puentes (PG-3). Artículo: 542-Mezclas bituminosas en caliente tipo hormigón bituminoso; 2008.

[28]. Ministerio de Obras Públicas y Transportes. Normas NLT. Ensayos de carreteras. Dirección General de Carreteras, second edition, Madrid, Spain; 2002.

[29]. Asphalt Institute. "Mix Design Methods. For Asphalt Concrete and Other Hot-Mix Types. MS-2. Sixth Edition"; 1997.

[30]. AENOR. Asociación Española de Normalización y Certificación. UNE-EN 12697-12 "Métodos de ensayo para mezclas bituminosas en caliente. Parte 12: Determinación de la sensibilidad al agua de las probetas de mezcla bituminosa". Madrid, Spain; 2006.

[31]. AENOR. Asociación Española de Normalización y Certificación. UNE-EN 12697-26 "Métodos de ensayo para mezclas bituminosas en caliente. Parte 26: Rigidez". Madrid, Spain; 2006.

[32]. BSi. British Standards Institution. Draft for Development DD 226:1996. "Method for determining resistance to permanent deformation of bituminous mixtures subject to unconfined dynamic loading"; 1996.

[33]. AENOR. Asociación Española de Normalización y Certificación. UNE-EN 12697-24: 2006+A1 "Métodos de ensayo para mezclas bituminosas en caliente. Parte 24: Resistencia a la fatiga". Madrid, Spain; 2006.

[34]. Khalid H.A. "A comparison between bending and diametral fatigue test for bituminous materials". Mater Struct 2000; 33: 457 - 465. 
[35]. Cocurullo A., Airey G.D., Collop A.C., Sangiorgi C. "Indirect Tensile versus Two-point Bending Fatigue Testing". Proceedings of the ICE - Transport 2008; 161 (4): 207-220.

[36]. Dirección General de Carreteras. Pliego de prescripciones técnicas generales para obras de carreteras y puentes PG-3. Ediciones Liteam, Madrid; Spain; 2002.

[37]. American Association of State Highway and Transportation Officials (AASHTO). Guide for design of pavement structures, Washington, D.C.; 1993.

[38]. Ministerio de Fomento. CEDEX. IECA. Manual de firmes con capas tratadas con cemento. 2003.

[39]. B.M.J.A. Verhaeghe, P.A. Myburgh, E. Denneman. Asphalt rutting and its prevention. Proceedings of $9^{\text {th }}$ Conference on Asphalt Pavements for Southern Africa; 2007.

[40]. He Gui-ping, Wong Wing-gun. "Laboratory study on permanent deformation of foamed asphalt mix incorporating reclaimed asphalt pavement materials". Constr Build Mater 2007; 21: 18091819.

[41]. Santagata F.A, Canestrari F., Pasquini E. Mechanical characterization of asphalt rubber-wet process. Proceedings of $4^{\text {th }}$ International SIV Congress. Palermo. Italy; 2007.

[42]. Aschuri Imam, Woodward David, Woodside Alan. Permanent deformation characteristics of asphalt concrete containing reclaimed materials. In: Sixth International Conference on Maintenance and Rehabilitation of Pavements and Technological Control, Politechnico di Torino, Italy; 2009; 1: 232-242. 
Figure 1

RCA used in this investigation: (a) Attached mortar and (b) Gypsum impurities

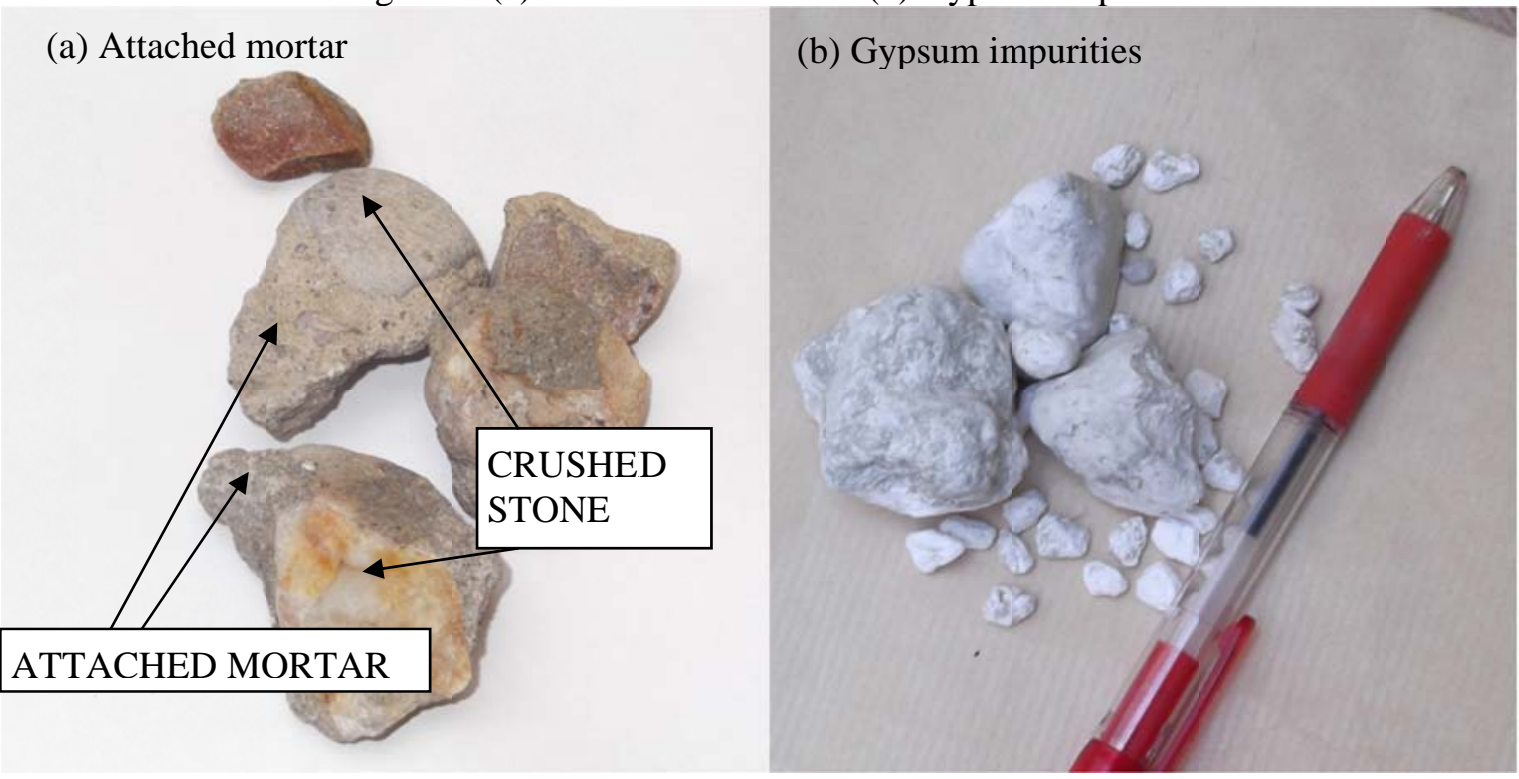


Figure 2

Gradation curve

Gradation curve of a AC 22 base G

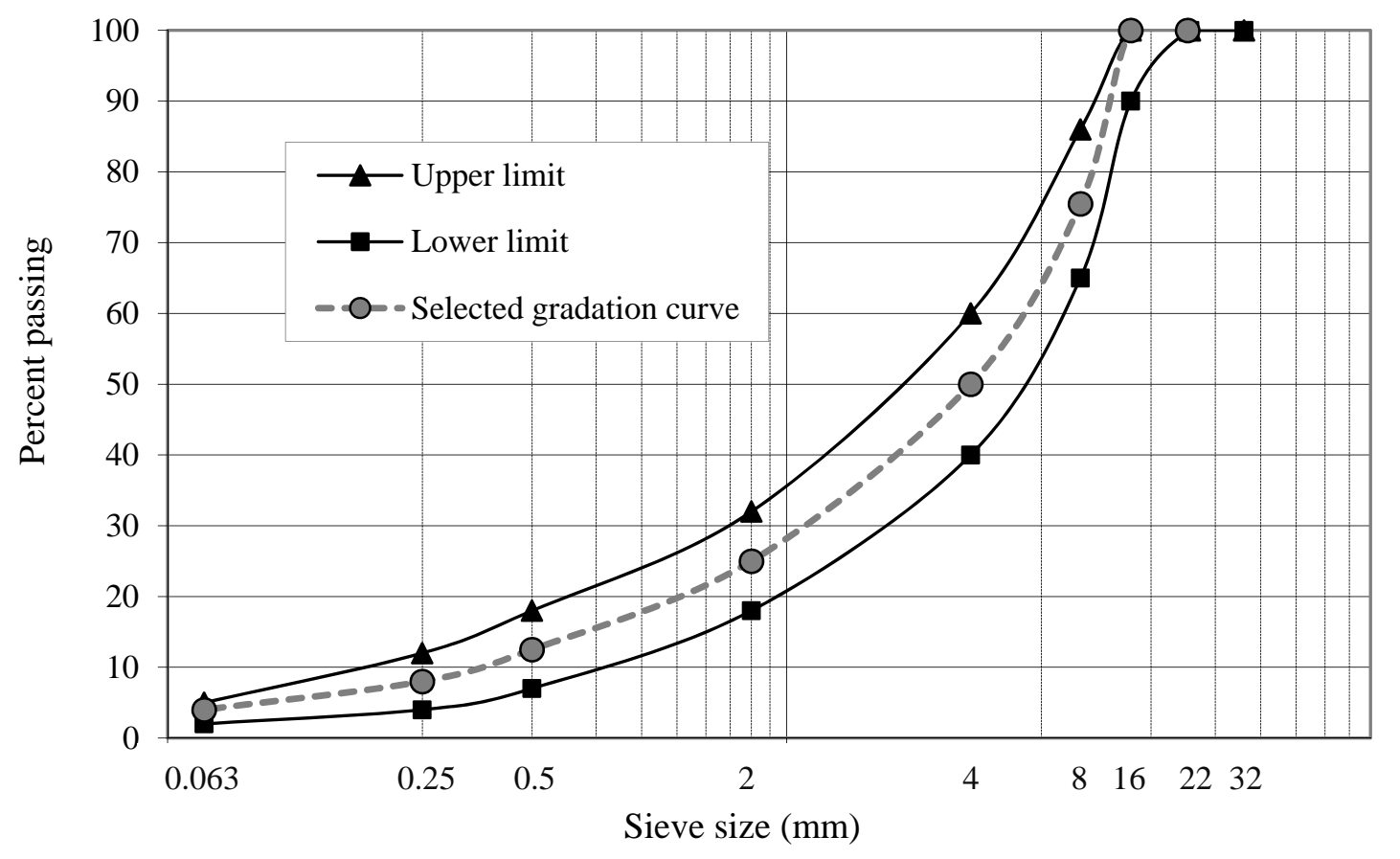


Figure 3

Moisture sensitivity test results

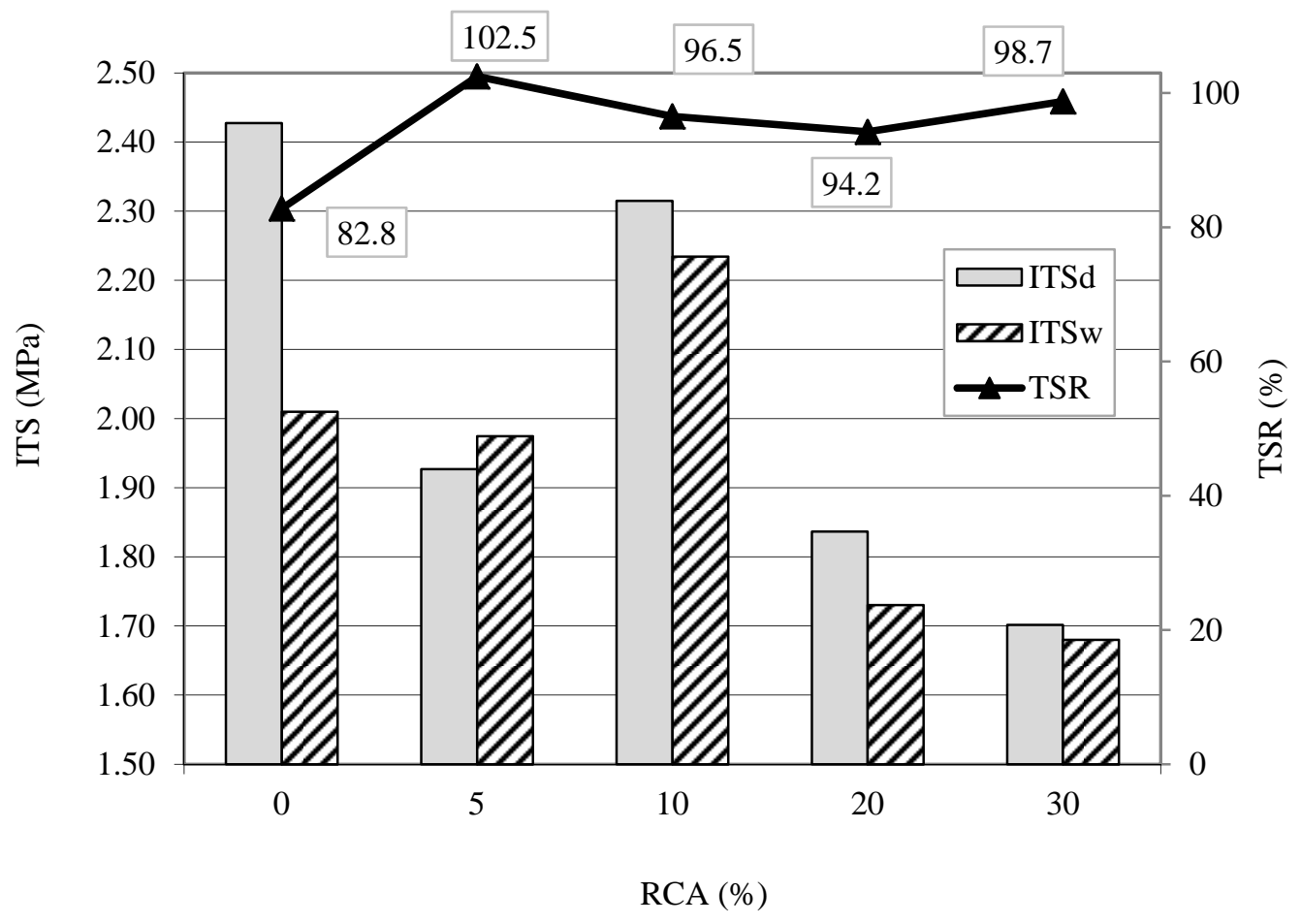


Figure 4

Resilient modulus

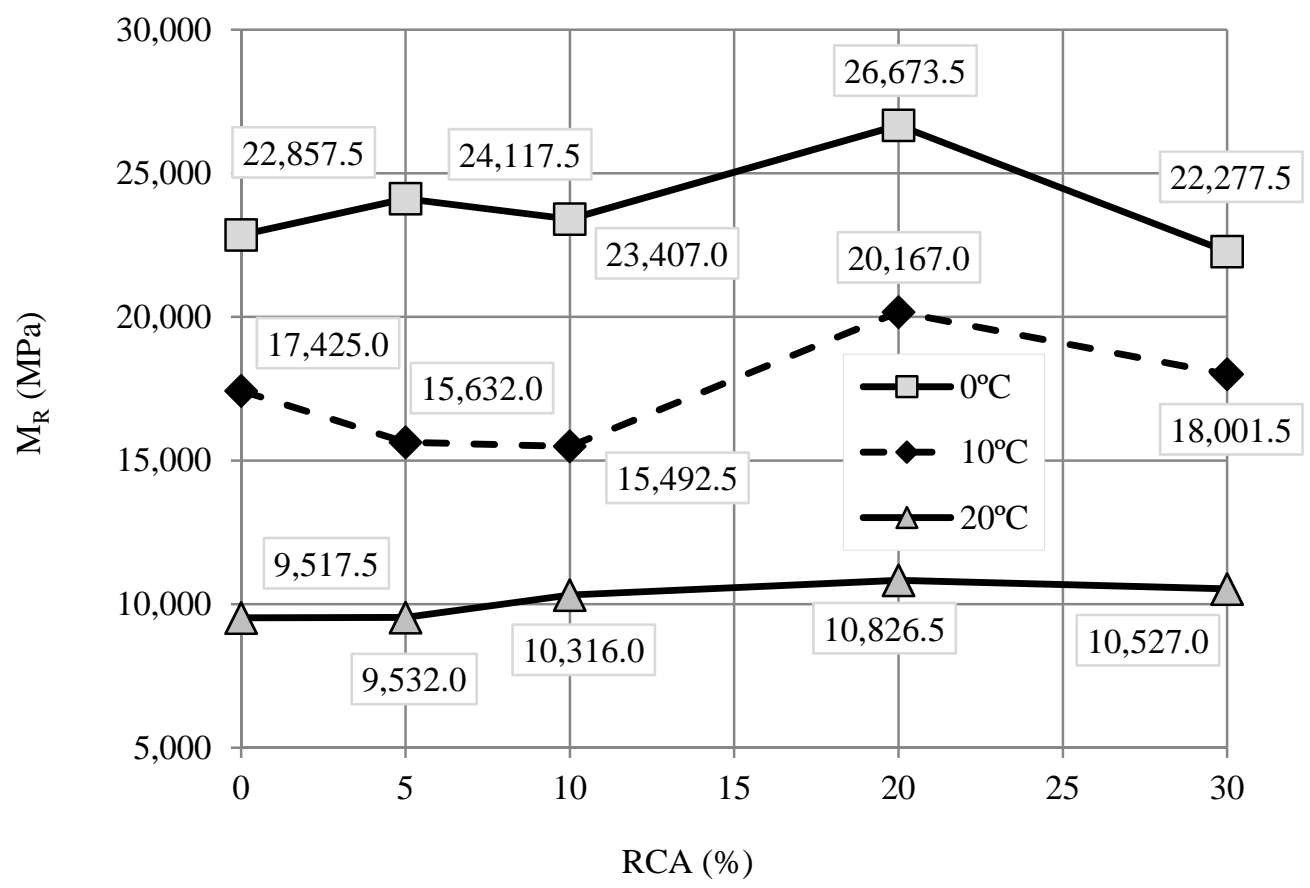


Figure 5

Accumulated permanent deformation through 1,800 cycles

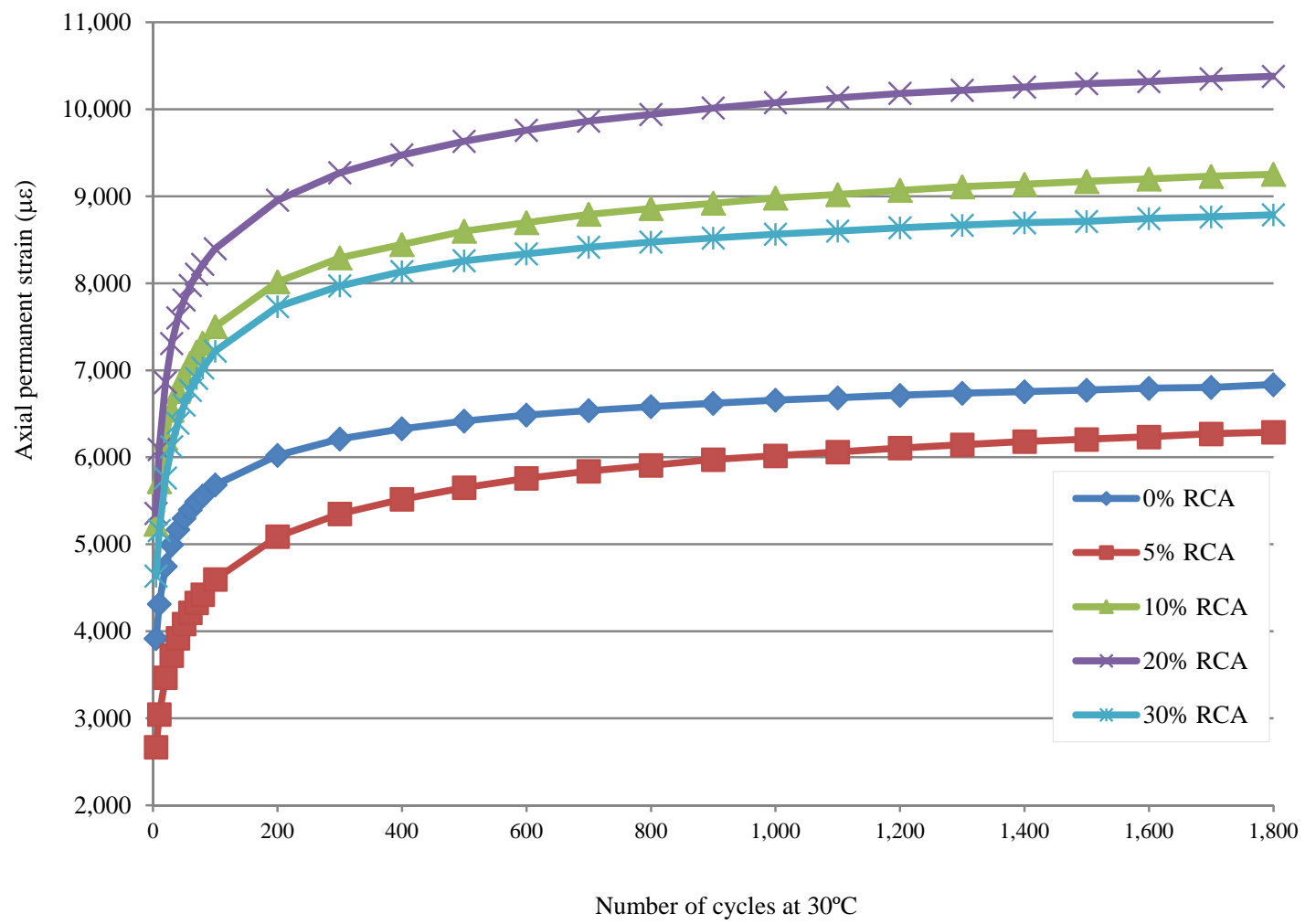


Figure 6

ITFT failure patterns: (a) Samples made with 0\% RCA and (b) Samples made with 30\% RCA.
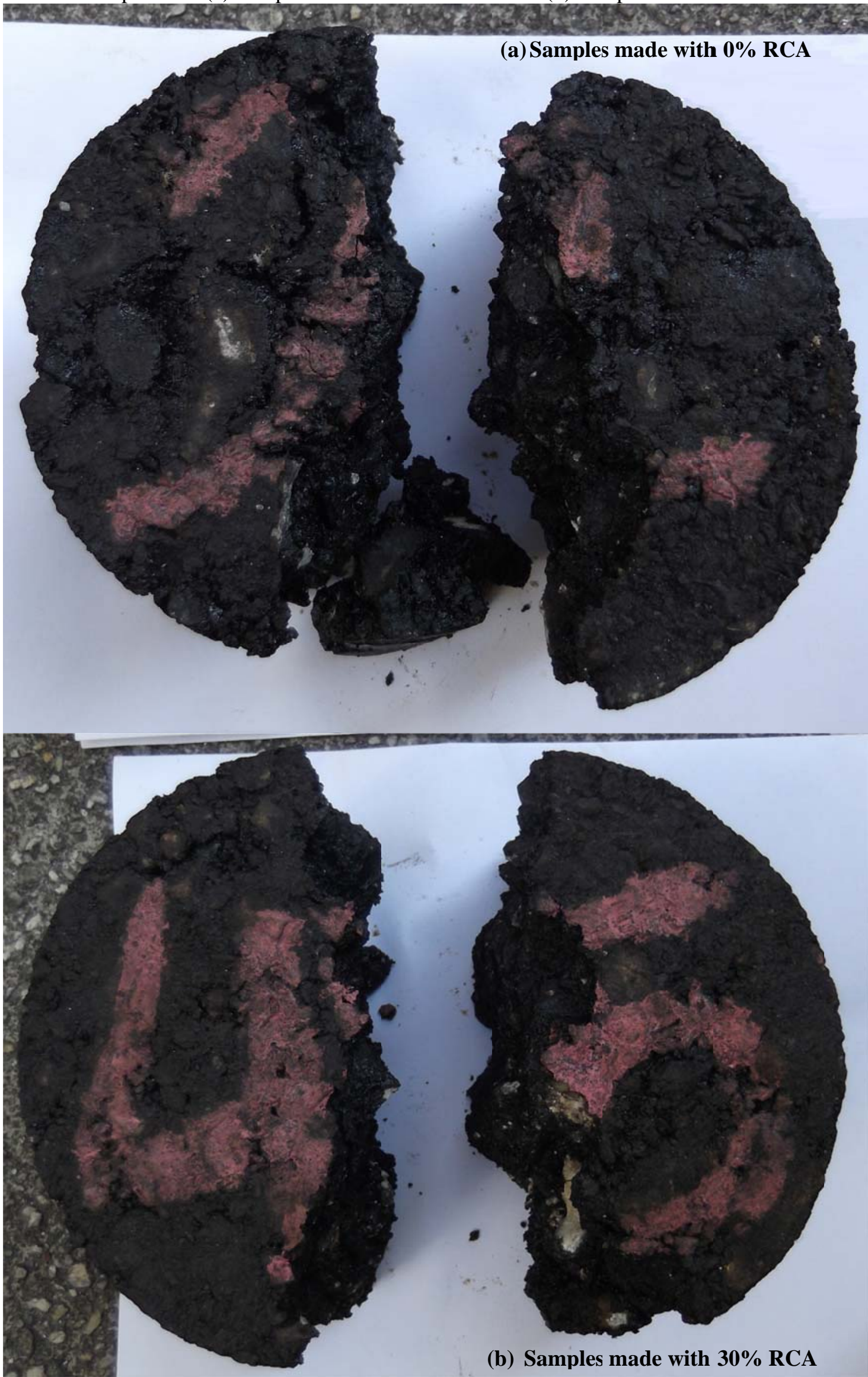
Figure 7

Fatigue life

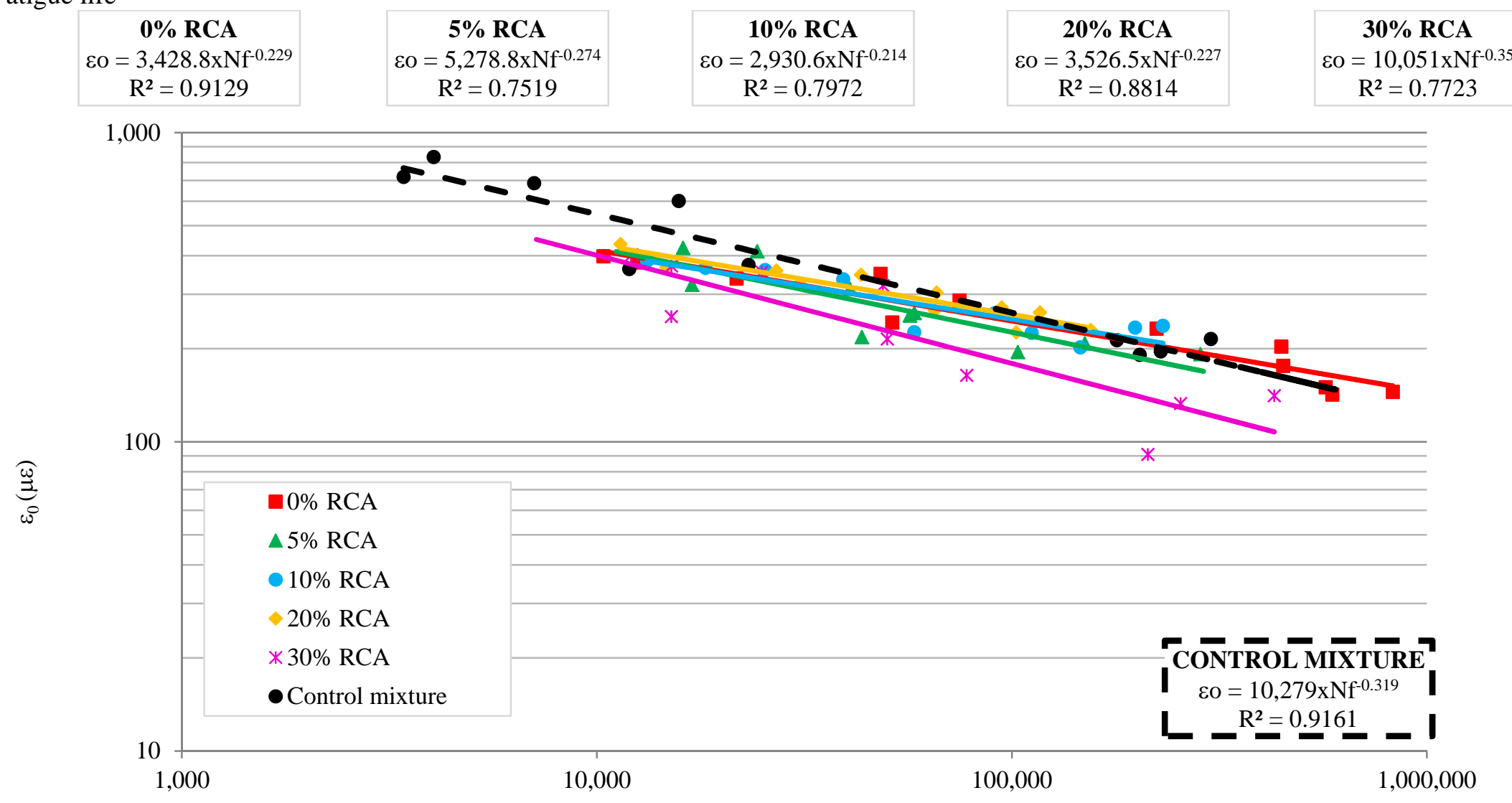

Cycles to failure (Nf) 
Table 1

Characterisation of aggregates

\begin{tabular}{lllllll}
\hline Aggregate & Standard & RCA & Hornfels & \multicolumn{3}{l}{ PG-3 Specifications $\left(^{*}\right)$} \\
\cline { 5 - 7 } & & & & T00-T1 & T3-T2 & T4 \\
\hline$\rho \mathrm{\rho a}\left(\mathrm{g} / \mathrm{cm}^{3}\right)$ & EN-1097-6 & 2.63 & 2.79 & - & - & - \\
$\mathrm{WA}_{24}(\%)$ & EN 1097-6 & 5.08 & 1.08 & - & - & - \\
$\mathrm{SE}(\%)$ & EN 933-8 & 67 & 61 & $\geq 50$ & $\geq 50$ & $\geq 50$ \\
LA abrasion (\%) & EN 1097-2 & 32 & 14.1 & $\leq 25$ & $\leq 30$ & - \\
\hline
\end{tabular}

(*) Traffic category T00 refers to AADHT (Annual Average Daily Heavy Traffic) $\geq 4,000$

Traffic category T0 refers to $4,000>$ AADHT $\geq 2,000$

Traffic category T1 refers to $2,000>$ AADHT $\geq 800$

Traffic category $\mathrm{T} 2$ refers to $800>$ AADHT $\geq 200$

Traffic category T3 refers to $200>$ AADHT $\geq 50$

Traffic category $\mathrm{T} 4$ refers to AADHT $<50$ 
Table 2

Properties of asphalt cement

\begin{tabular}{llcc}
\hline Test & Standard & B50/70 & $\begin{array}{c}\text { PG-3 } \\
\text { specification }\end{array}$ \\
\hline Original & & & \\
\hline Penetration $\left(100 \mathrm{~g}, 5 \mathrm{~s}, 25^{\circ} \mathrm{C}\right), 0.1 \mathrm{~mm}$ & NLT-124 & 52 & $50-70$ \\
Softening point, ${ }^{\circ} \mathrm{C}$ & UNE-EN 1427 & 54.9 & $48-57$ \\
Flash point, ${ }^{\circ} \mathrm{C}$ & ISO 2592 & $>290$ & $>235$ \\
Density $\left(25^{\circ} \mathrm{C}\right), \mathrm{g} / \mathrm{cm}^{3}$ & NLT-122 & 1.009 & $>1.0$ \\
\hline After rolling thin-film oven test & & & \\
\hline Penetration $\left(100 \mathrm{~g}, 5 \mathrm{~s}, 25^{\circ} \mathrm{C}\right), 0.1 \mathrm{~mm}$ & NLT-124 & 68 & $>50$ \\
$\Delta$ Softening point, ${ }^{\circ} \mathrm{C}$ & NLT-125 & 6.5 & $\leq 9$ \\
\hline
\end{tabular}


Table 3

HMA properties at optimum asphalt contents

\begin{tabular}{|c|c|c|c|c|c|c|c|c|c|}
\hline \multicolumn{6}{|c|}{$\begin{array}{l}\text { HMA oven-cured for } 4 \text { hours at } 170^{\circ} \mathrm{C} \text { before } \\
\text { compaction }\end{array}$} & \multicolumn{4}{|c|}{ PG-3 specifications } \\
\hline & $0 \%$ & $5 \%$ & $10 \%$ & $20 \%$ & $30 \%$ & T00-T0 & $\mathrm{T} 1-\mathrm{T} 2$ & T3 & T4 \\
\hline & RCA & $\mathrm{RCA}$ & RCA & $\mathrm{RCA}$ & RCA & & & & \\
\hline Вo (\%) & 4.00 & 3.80 & 3.90 & 4.40 & 4.30 & \multicolumn{4}{|c|}{$>3.5$} \\
\hline Pbe $(\%)$ & 3.05 & 2.67 & 2.66 & 2.77 & 2.33 & \multicolumn{4}{|c|}{-} \\
\hline $\mathrm{Pba}(\%)$ & 0.99 & 1.17 & 1.29 & 1.71 & 2.06 & \multicolumn{4}{|c|}{ - } \\
\hline $\mathrm{Va}(\%)$ & 7.25 & 7.57 & 7.27 & 7.87 & 7.71 & $5-8$ & $6-9$ & $5-9$ & - \\
\hline VMA $(\%)$ & 16.84 & 16.66 & 16.54 & 18.14 & 17.71 & \multicolumn{4}{|c|}{$\geq 14$} \\
\hline $\mathrm{VMA}_{\mathrm{abs}}(\%)$ & 14.53 & 14.00 & 13.51 & 14.31 & 13.17 & \multicolumn{4}{|c|}{-} \\
\hline VFA (\%) & 56.82 & 53.96 & 55.85 & 56.59 & 56.44 & \multicolumn{4}{|c|}{ - } \\
\hline $\mathrm{VFA}_{\mathrm{abs}}(\%)$ & 49.89 & 45.20 & 46.00 & 44.97 & 41.31 & \multicolumn{4}{|c|}{-} \\
\hline $\mathrm{S}(\mathrm{kN})$ & 17.31 & 19.41 & 16.83 & 16.78 & 17.66 & $>15$ & $>12.5$ & $>10$ & $8-12$ \\
\hline $\mathrm{F}(\mathrm{mm})$ & 2.02 & 2.22 & 2.51 & 2.14 & 2.54 & \multicolumn{3}{|c|}{ 2-3.5 } & $2.5-3.5$ \\
\hline $\mathrm{UW}\left(\mathrm{t} / \mathrm{m}^{3}\right)$ & 2.41 & 2.40 & 2.40 & 2.35 & 2.34 & \multicolumn{4}{|c|}{ - } \\
\hline $\mathrm{S} / \mathrm{F}(\mathrm{kN} / \mathrm{mm})$ & 8.57 & 8.75 & 6.71 & 7.85 & 6.96 & \multicolumn{4}{|c|}{ - } \\
\hline
\end{tabular}


Table 4

Slopes between cycles 600 and 1,800 in permanent deformation curves

\begin{tabular}{cc}
\hline RCA $(\%)$ & slope \\
\hline 0 & 0.29 \\
5 & 0.44 \\
10 & 0.46 \\
20 & 0.52 \\
30 & 0.37 \\
\hline
\end{tabular}

